\title{
FENOLOGIA DE ÁRVORES EM FRAGMENTO DE MATA EM SÃO PAULO, SP
}

\author{
FERRAZ, D. K., ${ }^{1}$ ARTES, R., ${ }^{2}$ MANTOVANI, W. ${ }^{1}$ e MAGALHÃES, L. M. ${ }^{2}$ \\ ${ }^{1}$ Departamento de Ecologia Geral, USP, CEP 05508-900, São Paulo, SP \\ ${ }^{2}$ Instituto de Matemática e Estatística, USP, CEP 05508-900, São Paulo, SP \\ Correspondência para: Waldir Mantovani, Departamento de Ecologia Geral, Instituto de Biociências, Rua do \\ Matão, Trav. 14, 321, CEP 05508-900, São Paulo, SP, e-mail: wmantova@ib.usp.br \\ Recebido em 02/07/97 - Aceito em 20/07/98 - Distribuído em 30/06/99
}

(Com 1 figura)

\begin{abstract}
Phenology of tree species in an urban forest fragment in São Paulo, SP

The phenology of six tree species was studied from October 1993 to October 1996, in a forest fragment (10 ha) located in the metropolitan region of São Paulo City (aproximately $46^{\circ} 43^{\prime} \mathrm{W}$ and $23^{\circ} 33^{\prime} \mathrm{S}$; $750 \mathrm{~m}$ of mean altitude). Individuals of Alchornea sidifolia, Cecropia glaziouii, Cedrela fissilis, Cordia ecalyculata, Croton floribundus and Cupania oblongifolia were observed about the time of occurrence of flowering, fruiting, leaf fall, and flushing. Descriptive circular analysis was carried out for the time of occurrence, as well as multiple correlation coeficients were determined in order to investigate the relationship between temperature and rainfall and phenological events. The strongest relationship was found between the fruiting season and climate for $C$. ecalyculata, followed by $C$. floribundus. The factors related to the time of occurrence, duration, periodicity and sincrony of the phenological events are discussed.
\end{abstract}

Key words: phenology, tree species, forest fragment, Southeastern Brazil.

\section{RESUMO}

A fenologia de 6 espécies arbóreas foi estudada de outubro de 1993 a outubro de 1996, em um fragmento de floresta ( 10 ha) na região metropolitana de São Paulo (aproximadamente $46^{\circ} 43^{\prime} \mathrm{W}$ e $23^{\circ} 33^{\prime}$ 'S; $750 \mathrm{~m}$ de altitude média). Foram acompanhados indivíduos de Alchornea sidifolia, Cecropia glaziouii, Cedrela fissilis, Cordia ecalyculata, Croton floribundus e Cupania oblongifolia, e observado o período de ocorrência das fenofases: floração, frutificação, queda e brotamento de folhas. Foi realizada a análise descritiva circular da época de ocorrência das fenofases e determinados os coeficientes de correlação múltipla entre a precipitação, a temperatura e as fenofases, para investigar a influência destes fatores do clima na fenologia das espécies. A relação mais forte foi encontrada entre a frutificação e o clima em C. ecalyculata, seguida por C. floribundus. São discutidos os fatores relacionados com a época de ocorrência, duração, periodicidade e sincronia dos eventos fenológicos.

Palavras-chave: fenologia, espécies arbóreas, fragmento florestal, Sudeste do Brasil.

\section{INTRODUÇÃO}

A época em que acontecem os eventos reprodutivos nas plantas é determinante para o sucesso da população, ao assegurar a sobrevivência e o estabelecimento dos indivíduos jovens. A fenologia das espécies é regulada pelas suas caracte- rísticas endógenas associadas às variações do clima, além de fatores abióticos e bióticos que são fatores de pressão seletiva para o desenvolvimento de padrões fenológicos (Janzen, 1967, 1975; Rathcke \& Lacey, 1985).

A fenologia de espécies de plantas tem sido relativamente pouco estudada em regiões tropi- 
cais e faltam termos e métodos padronizados. Existe pouca informação de pesquisas de longo prazo; geralmente os estudos são curtos e misturam os níveis de análise (individual, populacional e da comunidade), tentando descrever padrões complexos, diversos e irregulares (Newstrom et al., 1994).

A maioria dos trabalhos nos trópicos tem sido conduzida em nível de comunidade com o objetivo de entender os ciclos de disponibilidade de recursos para os animais (Newstrom et al., 1994; van Schaik et al., 1993).

$\mathrm{Na}$ região do presente estudo existem alguns estudos fenológicos desenvolvidos, principalmente, na Serra do Japi (Morellato \& Leitão-Filho, 1990, 1992; Morellato et al., 1989, 1990), e alguns na grande São Paulo (Penhalber, 1995; Rossi, 1994). Esses estudos detectaram que o período de maior floração acontece na transição entre as épocas seca e úmida, de setembro a novembro, apesar de tratarem de tipos florestais diferentes.

A frutificação, porém, depende das características dos frutos e da síndrome de dispersão das espécies, bem como do estrato ocupado pelos indivíduos adultos (Morellato \& Leitão-Filho, 1990, 1992).

Outro fator relevante refere-se ao grupo ecológico a que pertence a espécie, determinando sua estratégia reprodutiva.

Além das características intrínsecas das espécies, as variações climáticas também influenciam a fenologia, regulando a época, a intensidade, a duração e a periodicidade dos eventos fenológicos. No entanto, ainda são poucos os estudos que testam a influência do clima na época de ocorrência das fenofases (Alencar, 1994; Pereira et al., 1995; Reich \& Borchert, 1984), enquanto a maioria dos trabalhos apenas descreve e compara os resultados sem fazer uso de métodos estatísticos.

O presente estudo pretendeu conhecer o padrão fenológico de espécies características de diferentes estádios sucessionais, de acordo com os seguintes objetivos: 1) caracterizar a época de floração, frutificação, queda e brotamento de folhas de algumas populações de árvores, com principal interesse na época e periodicidade dos eventos reprodutivos; e 2) relacionar a freqüência de ocorrência das fenofases às condições climáticas do período.

\section{MATERIAIS E MÉTODOS}

\section{Área e espécies em estudo}

$\mathrm{O}$ estudo foi realizado na mata da Reserva da Cidade Universitária “Armando de Salles Oliveira" (CUASO), que possui área aproximada de 10 ha e está situada na região metropolitana de São Paulo, SP. Esse fragmento encontra-se em altitude média de $750 \mathrm{~m}$, próximo às coordenadas $46^{\circ} 43^{\prime} \mathrm{W}$ e $23^{\circ} 33^{\prime} \mathrm{S}$.

O clima da região é do tipo Cwa ou temperado chuvoso (Koeppen, 1948), com precipitação média anual em torno de $1.500 \mathrm{~mm}$. As maiores temperaturas ocorrem entre novembro e abril, com pico em janeiro. Este período mais quente contém o mais úmido, de dezembro a março, com pequenas variações entre os anos (Gomes, 1992). As épocas mais frias correspondem às de menor precipitação, de maio a agosto. Durante o período de estudo, somente os meses de setembro e de outubro de 1994 apresentaram deficiência hídrica no solo (Ferraz, 1997). Nos outros anos, a estação menos chuvosa caracterizou-se pela menor precipitação em relação à evapotranspiração potencial, com utilização de reservas de água do solo. A maior parte do período estudado apresentou excedente hídrico. Os meses de abril e de setembro até novembro são transicionais, sendo que o primeiro corresponde ao início da época seca e os últimos, da úmida.

De acordo com Veloso \& Góes-Filho (1982), essa mata situa-se no domínio da floresta ombrófila densa. Entretanto, Gomes (1992) considera que esta região se encontra sob clima com características transicionais, resultando na existência de floresta ecotonal, com elementos da floresta ombrófila densa Atlântica e das matas estacionais semidecíduas do interior do estado.

As observações fenológicas foram realizadas em espécies selecionadas por apresentarem características ecológicas diferentes entre si: Alchornea sidifolia Muell. Arg. (Euphorbiaceae), Cecropia glaziouii Sneth (Cecropiaceae), Cedrela fissilis Vell. (Meliaceae), Cordia ecalyculata Vell. (Boraginaceae), Croton floribundus Spreng. (Euphorbiaceae) e Cupania oblongifolia Mart. (Sapindaceae) (Tabela 1). No decorrer do trabalho, as espécies serão denominadas pelo seu nome genérico. 
TABELA 1

Espécies em estudo, grupo ecológico a que pertencem, estrato ocupado, síndrome de dispersão e abundância na área de estudo (Cersósimo, 1993; Roizman, 1993).

\begin{tabular}{|c|c|c|c|c|}
\hline Espécies & $\begin{array}{c}\text { Grupo } \\
\text { ecológico }\end{array}$ & $\begin{array}{c}\text { Estrato } \\
\text { ocupado }\end{array}$ & $\begin{array}{l}\text { Síndrome de } \\
\text { dispersão }\end{array}$ & $\begin{array}{c}\text { Abundância na } \\
\text { mata da CUASO }\end{array}$ \\
\hline $\begin{array}{l}\text { Alchornea sidifolia Muell. } \\
\text { (Euphorbiaceae) }\end{array}$ & Pioneira & Dossel & Zoocoria & $\begin{array}{l}\text { Estrato arbóreo, chuva } \\
\text { e banco de sementes }\end{array}$ \\
\hline $\begin{array}{l}\text { Cecropia glaziouii Sneth. } \\
\text { (Cecropiaceae) }\end{array}$ & Pioneira & Dossel & Zoocoria & $\begin{array}{l}\text { Chuva e banco } \\
\text { de sementes }\end{array}$ \\
\hline $\begin{array}{l}\text { Cedrela fissilis Vell. } \\
\text { (Meliaceae) }\end{array}$ & $\begin{array}{l}\text { Secundária } \\
\text { tardia }\end{array}$ & Dossel & Anemocoria & $\begin{array}{l}\text { Estrato arbóreo e } \\
\text { sub-bosque }\end{array}$ \\
\hline $\begin{array}{l}\text { Cordia ecalyculata Vell. } \\
\text { (Boraginaceae) }\end{array}$ & $\begin{array}{l}\text { Secundária } \\
\text { tardia }\end{array}$ & Subdossel & Zoocoria & Estrato arbóreo \\
\hline $\begin{array}{l}\text { Croton floribundus } \\
\text { Spreng.(Euphorbiaceae) }\end{array}$ & $\begin{array}{l}\text { Secundária } \\
\text { inicial }\end{array}$ & Dossel & Autocoria & Plântulas \\
\hline $\begin{array}{l}\text { Cupania oblongifolia } \\
\text { Mart.(Sapindaceae) }\end{array}$ & Climácica & Subdossel & Zoocoria & Estrato arbóreo \\
\hline
\end{tabular}

\section{Fenologia}

Foram acompanhados 29 indivíduos, sendo 4 de Cecropia e 5 de Alchornea, Cedrela, Cordia, Croton e de Cupania. Foram selecionados os maiores indivíduos na tentativa de assegurar que todos fossem adultos. A ocorrência das fenofases floração, frutificação, queda e brotamento de folhas foi observada com o auxílio de binóculo, em intervalos de 20 dias, de outubro de 1993 a outubro de 1996. Por floração entendeu-se a presença de flores, sem distinguir entre botão floral e flor aberta, no mínimo em um indivíduo. Em Cecropia foi observada apenas a presença de espigas. Foram observadas as folhas caídas sob os indivíduos e também a situação da copa para caracterizar a queda de folhas.

Foram construídos gráficos de freqüência das fenofases por mês, para cada espécie. Por freqüência entendeu-se a proporção de indivíduos apresentando determinada fenofase a cada mês, considerando os dados de todos os anos de estudo. Para a análise da época de ocorrência dos eventos fenológicos, foram utilizadas técnicas de análise de dados circulares, da seguinte maneira: 1) os dias do ano (0-365) foram convertidos em graus (0-360); 2) calculou-se a freqüência de ocorrência das fenofases associadas a cada grau da circunferência, para todas as espécies; 3 ) a direção e o tamanho (norma) do vetor médio foram calculados para cada fenofase, em todas as espécies; 4) foi calculada a variância circular ou dispersão dos eventos fenológicos; e 5) a data média foi con- vertida a partir do ângulo médio (Fisher, 1993; Windsor et al., 1989).

Para investigar a influência dos fatores climáticos na fenologia das espécies foram determinados coeficientes de correlação de Pearson $\left(\mathrm{r}_{\mathrm{p}}\right)$ (Bussab \& Morettin, 1986) e de correlação múltipla (R) (Montgomery \& Peck, 1982) entre a freqüência de ocorrência das fenofases e alguns elementos do clima. O coeficiente de correlação múltipla mediu a relação conjunta da precipitação e da temperatura, verificando se existia associação linear entre as variáveis climáticas e a freqüência das fenofases, não evidenciando o sentido da relação (positivo ou negativo). Por meio do sinal do coeficiente de correlação de Pearson é possível conhecer o sentido da relação e, portanto, as duas análises se complementam. Verificou-se a relação entre os elementos do clima no mesmo mês, no primeiro e no segundo meses anteriores ao evento fenológico. Utilizou-se o teste não-paramétrico de Runs (Gibbons, 1981) para testar se a freqüência de ocorrência das fenofases depende (linearmente ou não) da precipitação e/ou da temperatura.

Os dados de precipitação e de temperatura foram obtidos na Estação Meteorológica do Instituto Astronômico e Geofísico (IAG) da USP, distante cerca de $15 \mathrm{~km}$ da área de estudo.

\section{RESULTADOS}

Alchornea apresentou floração subanual, com mais de um ciclo de produção de flores a cada ano. 
A época de floração estendeu-se desde o início da estação seca até o início da estação úmida (pico em setembro), época em que também foram produzidos os frutos (pico em outubro) (Fig. 1a). A espécie apresentou queda e brotamento de folhas durante o ano todo. Em Cecropia, a produção de espigas foi contínua durante $o$ ano, mas a freqüência de indivíduos com espigas foi baixa em todos os meses. A queda e o brotamento de folhas foram muito freqüentes durante o ano inteiro (Fig. 1b).

Cedrela floresceu de outubro a dezembro (pico em novembro), imediatamente após o brotamento das folhas, que aconteceu em setembro e outubro (Fig. 1c). A espécie parece apresentar um padrão supra-anual (bianual) de floração, sendo que apenas um indivíduo floresceu em 1994. Os frutos apresentaram um longo período de maturação, de dezembro a abril, estando maduros de maio a outubro (Figura 1c). Apesar de observarem-se folhas caídas durante o ano inteiro, a intensidade foi muito variável. A perda de folhas era geralmente reduzida, aumentando a partir de maio, estando as copas completamente sem folhas de junho a agosto, coincidindo com o período de dispersão das sementes.

Cordia apresentou perfeita correspondência da época de ocorrência das fenofases entre os diferentes anos de estudo. A floração ocorreu de outubro a dezembro, com um ciclo principal a cada ano, ou seja, padrão anual. A frutificação seguiu a floração, entre dezembro e abril (Fig. 1d). A espécie perdeu folhas e brotou durante o ano inteiro, sendo que o brotamento diminuiu na estação seca, de junho a setembro. A floração em Croton foi mais freqüente em novembro e dezembro e ocorreu anualmente; a frutificação aconteceu de dezembro a maio, sendo que a maioria dos indivíduos produziu frutos em dezembro e janeiro. A duração dessas fenofases variou entre os anos. A queda e o brotamento de folhas ocorreram continuamente, havendo uma diminuição no brotamento de julho até setembro (Fig. 1e).

Os indivíduos observados de Cupania não apresentaram flores nem frutos durante o período de estudo, o que pode caracterizar um padrão de reprodução supra-anual ou a inexistência de adultos na amostra. Essa espécie perdeu folhas durante o ano todo e apresentou alguns períodos de brotamento, com picos em dezembro e abril. O resultado da análise descritiva circular está apre- sentado na Tabela 2, que fornece a data média de ocorrência de cada evento, a concentração das fenofases em torno dessa média (comprimento da resultante média ou r) e a dispersão das fenofases em relação à época média (variância circular ou 1-r). Podemos notar que Alchornea, Cecropia, Cordia, Croton e Cupania apresentaram grande dispersão (acima de 80\%) das épocas de queda e brotamento de folhas em relação à data média, o que significa que a ocorrência desses eventos aconteceu por períodos extensos. Em Cedrela, o brotamento concentrou-se em outubro ( $3 \%$ de dispersão dos dados). Cedrela, Cordia e Croton possuíram floração concentrada em novembro, com dispersão de apenas $5 \%$ a $8 \%$ dos dados.

A frutificação concentrou-se em julho em Cedrela, fevereiro em Cordia e em janeiro em Croton, apresentando uma variação de cerca de $25 \%$ em torno dessas épocas médias. Cecropia apresentou produção de espigas dispersa por todo o ano (dispersão igual a 90\%) e Alchornea apresentou floração e frutificação relativamente dispersas durante o ano, em torno de $50 \%$, o que sugere um padrão bimodal de ocorrência dessas fenofases.

Os coeficientes de correlação múltipla (Tabela 3) evidenciaram uma relação mais forte entre as variáveis climáticas e a freqüência de ocorrência das fenofases, quando comparados com os coeficientes de correlação de Pearson (Tabela 4), que não levaram em conta a temperatura e a precipitação conjuntamente.

A floração em Croton apresentou relação com os elementos do clima de dois meses anteriores à sua ocorrência $(\mathrm{R}=0,66)$, da mesma forma que $\operatorname{Cordia}(\mathrm{R}=0,65)$ e Cedrela $(\mathrm{R}=0,51)$. A frutificação esteve associada aos fatores do clima no período de produção dos frutos. As relações mais fortes foram encontradas em Cordia $(\mathrm{R}=0,78)$, sendo que, quanto maior a precipitação e a temperatura, maior foi a proporção de árvores com frutos $\left(r_{\mathrm{P}}=0,76\right.$ e $\mathrm{r}_{\mathrm{P}}=0,67$, respectivamente). Croton e Cedrela também apresentaram esse padrão de associação entre a frutificação e os elementos do clima ( $\mathrm{R}=0,69$ e $\mathrm{R}=0,61$, respectivamente). O brotamento em Cupania e Cordia esteve associado ao clima no período de produção de folhas ( $R=0,69$ e $R=0,56$, respectivamente), enquanto em Cedrela a associação se deu com o clima de dois meses anteriores ao brotamento $(\mathrm{R}=0,58)$. 


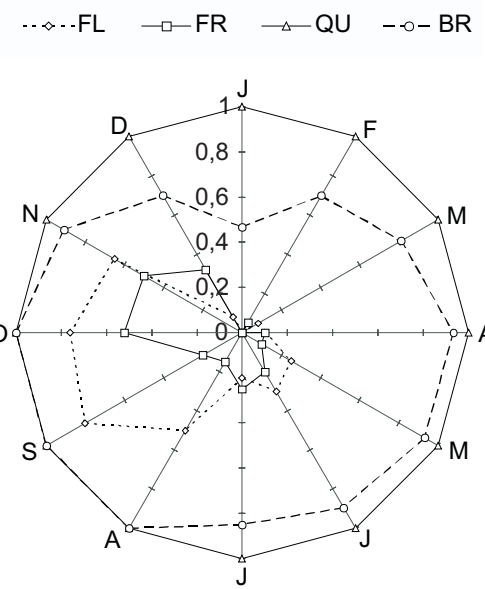

c)

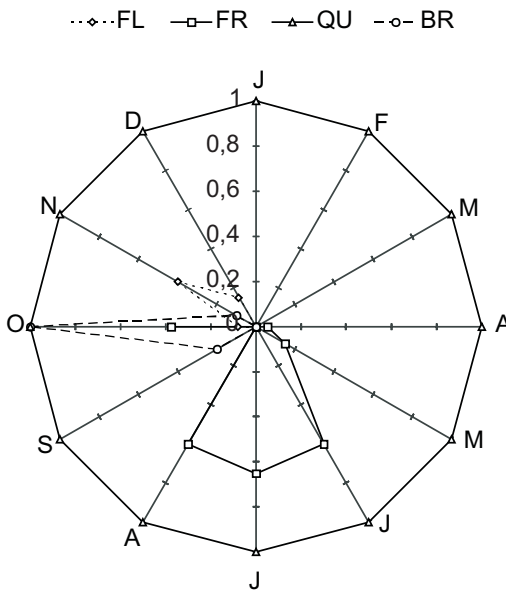

e)

$\therefore \rightarrow \mathrm{FL} \rightarrow \mathrm{FR} \rightarrow \triangle \mathrm{QU}-. \mathrm{B} \mathrm{BR}$

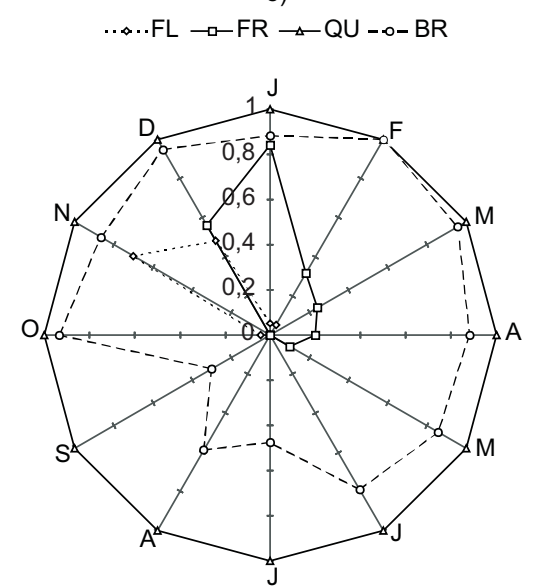

b)<smiles>[R8]O[Hg]O[As]</smiles>

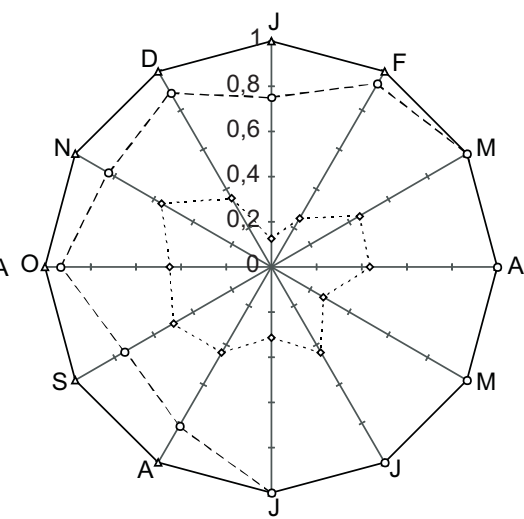

d)

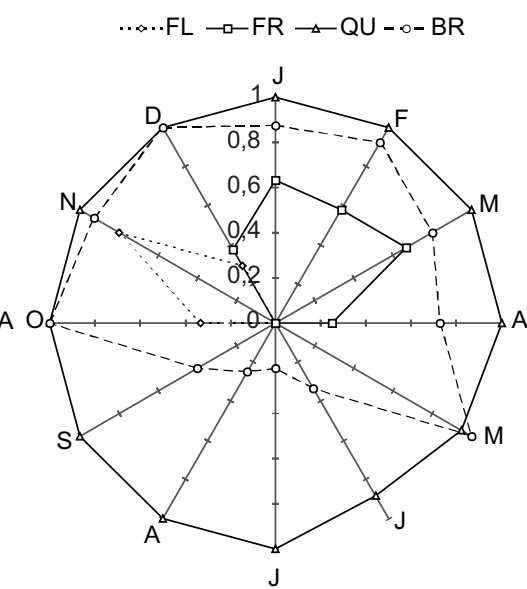

Fig. 1 - Freqüência de ocorrência das fenofases nas espécies em estudo. Os valores médios mensais de freqüência, do período de outubro de 1993 a outubro de 1996, são mostrados ao longo dos doze raios da circunferência, que representam os meses do ano (J-janeiro até D-dezembro). A freqüência de indivíduos apresentando determinada fenofase varia de 0 , no centro, até 1, no raio da circunferência. a) Alchornea; b) Cecropia; c) Cedrela; d) Cordia; e e) Croton. FL = floração; FR = frutificação; $\mathrm{ES}=$ presença de espiga; $\mathrm{QU}=$ queda de folhas; $\mathrm{e} \mathrm{BR}=$ brotamento. 
TABELA 2

Análise descritiva circular da época de ocorrência das fenofases nas espécies de estudo na Reserva da CUASO, São Paulo, SP.

\begin{tabular}{|c|c|c|c|c|c|c|}
\hline Espécie & Fenofase & $\begin{array}{c}\text { Média circular } \\
\text { (em dias) }\end{array}$ & Dia & Mês & $\begin{array}{l}\text { Resultante } \\
\text { média ( } r \text { ) }\end{array}$ & $\begin{array}{c}\text { Variância } \\
\text { circular (1-r) }\end{array}$ \\
\hline \multirow{4}{*}{ Alchornea } & Floração & 259 & 15 & 9 & 0,54 & 0,46 \\
\hline & Frutificação & 281 & 7 & 10 & 0,44 & 0,56 \\
\hline & Folhas caídas & 51 & 21 & 2 & 0,01 & 0,99 \\
\hline & Brotamento & 213 & 30 & 7 & 0,09 & 0,91 \\
\hline \multirow{3}{*}{ Cecropia } & Espigas & 249 & 5 & 9 & 0,10 & 0,90 \\
\hline & Folhas caídas & 51 & 20 & 2 & 0,01 & 0,99 \\
\hline & Brotamento & 119 & 28 & 4 & 0,06 & 0,94 \\
\hline \multirow{4}{*}{ Cedrela } & Floração & 323 & 17 & 11 & 0,95 & 0,05 \\
\hline & Frutificação & 203 & 21 & 7 & 0,73 & 0,27 \\
\hline & Folhas caídas & 122 & 1 & 5 & 0,04 & 0,96 \\
\hline & Brotamento & 286 & 11 & 10 & 0,97 & 0,03 \\
\hline \multirow{4}{*}{ Cordia } & Floração & 318 & 13 & 11 & 0,94 & 0,06 \\
\hline & Frutificação & 42 & 11 & 2 & 0,81 & 0,19 \\
\hline & Folhas caídas & 360 & 25 & 12 & 0,02 & 0,98 \\
\hline & Brotamento & 19 & 19 & 1 & 0,24 & 0,76 \\
\hline \multirow{4}{*}{ Croton } & Floração & 334 & 29 & 11 & 0,92 & 0,08 \\
\hline & Frutificação & 28 & 27 & 1 & 0,76 & 0,24 \\
\hline & Folhas caídas & 51 & 20 & 2 & 0,01 & 0,99 \\
\hline & Brotamento & 43 & 11 & 2 & 0,15 & 0,85 \\
\hline \multirow{2}{*}{ Cupania } & Folhas caídas & - & - & - & 0,01 & 0,99 \\
\hline & Brotamento & 32 & 1 & 2 & 0,22 & 0,78 \\
\hline
\end{tabular}

TABELA 3

Índices de correlação múltipla (R) entre as fenofases e as variáveis climáticas.

\begin{tabular}{|c|c|c|c|c|}
\hline Espécie & Fenofase & Clima 0 & Clima 1 & Clima2 \\
\hline \multirow[t]{3}{*}{ Alchornea } & Floração & 0,44 & 0,11 & 0,23 \\
\hline & Frutificação & 0,18 & 0,17 & 0,48 \\
\hline & Brotamento & 0,37 & 0,33 & 0,18 \\
\hline \multirow[t]{2}{*}{ Cecropia } & Espigas & 0,26 & 0,47 & 0,15 \\
\hline & Brotamento & 0,15 & 0,50 & 0,42 \\
\hline \multirow[t]{4}{*}{ Cedrela } & Floração & 0,24 & 0,37 & 0,51 \\
\hline & Frutificação & 0,61 & 0,52 & 0,24 \\
\hline & Folhas caídas & 0,25 & 0,27 & 0,35 \\
\hline & Brotamento & 0,16 & 0,56 & 0,58 \\
\hline \multirow[t]{4}{*}{ Cordia } & Floração & 0,20 & 0,43 & 0,65 \\
\hline & Frutificação & 0,78 & 0,54 & 0,11 \\
\hline & Folhas caídas & 0,29 & 0,46 & 0,42 \\
\hline & Brotamento & 0,56 & 0,53 & 0,41 \\
\hline \multirow[t]{3}{*}{ Croton } & Floração & 0,42 & 0,54 & 0,66 \\
\hline & Frutificação & 0,69 & 0,55 & 0,29 \\
\hline & Brotamento & 0,49 & 0,42 & 0,33 \\
\hline Cupania & Brotamento & 0,69 & 0,40 & 0,12 \\
\hline
\end{tabular}

Clima 0 = precipitação e temperatura no mesmo mês em que ocorre o evento fenológico.

Clima 1 = precipitação e temperatura no mês anterior ao evento.

Clima 2 = precipitação e temperatura de dois meses anteriores. 
TABELA 4

Índices de correlação de Pearson $\left(\mathrm{r}_{\mathrm{p}}\right)$ entre as fenofases e as variáveis climáticas.

\begin{tabular}{|c|c|c|c|c|c|c|c|}
\hline Espécie & Fenofase & Precip. 0 & Precip. 1 & Precip. 2 & Temp. 0 & Temp. 1 & Temp. 2 \\
\hline \multirow{3}{*}{ Alchornea } & Floração & $-0,41$ & $-0,05$ & 0,21 & $-0,37$ & $-0,13$ & 0,20 \\
\hline & Frutificação & $-0,18$ & 0,11 & 0,48 & $-0,12$ & 0,17 & 0,36 \\
\hline & Brotamento & $-0,34$ & $-0,34$ & $-0,15$ & $-0,17$ & $-0,18$ & $-0,06$ \\
\hline \multirow{2}{*}{ Cecropia } & Espigas & $-0,21$ & $-0,31$ & $-0,09$ & $-0,05$ & 0,01 & 0,01 \\
\hline & Brotamento & $-0,14$ & $-0,44$ & $-0,42$ & $-0,07$ & $-0,17$ & $-0,27$ \\
\hline \multirow{4}{*}{ Cedrela } & Floração & 0,01 & 0,28 & 0,49 & 0,17 & 0,38 & 0,47 \\
\hline & Frutificação & $-0,17$ & 0,0 & $-0,43$ & $-0,29$ & $-0,34$ & $-0,29$ \\
\hline & Folhas caídas & $-0,19$ & $-0,20$ & $-0,32$ & $-0,05$ & $-0,27$ & $-0,33$ \\
\hline & Brotamento & 0,03 & $-0,07$ & 0,22 & 0,13 & 0,37 & 0,52 \\
\hline \multirow{4}{*}{ Cordia } & Floração & 0,05 & 0,32 & 0,62 & 0,17 & 0,43 & 0,60 \\
\hline & Frutificação & 0,76 & 0,53 & 0,07 & 0,67 & 0,50 & 0,11 \\
\hline & Folhas caídas & 0,16 & 0,22 & 0,23 & 0,29 & 0,43 & 0,40 \\
\hline & Brotamento & 0,31 & 0,28 & 0,16 & 0,55 & 0,51 & 0,37 \\
\hline \multirow{3}{*}{ Croton } & Floração & 0,18 & 0,43 & 0,65 & 0,39 & 0,54 & 0,56 \\
\hline & Frutificação & 0,67 & 0,53 & 0,28 & 0,59 & 0,49 & 0,27 \\
\hline & Brotamento & 0,35 & 0,18 & 0,04 & 0,51 & 0,38 & 0,23 \\
\hline Cupania & Brotamento & 0,07 & 0,05 & 0,09 & 0,54 & 0,36 & 0,17 \\
\hline
\end{tabular}

Precip. 0 = precipitação no mesmo mês em que ocorre o evento fenológico. Precip. 1 = precipitação no mês anterior. Precip. $2=$ precipitação de dois meses anteriores. Temp. $0=$ temperatura média do mês em que ocorre a fenofase.

Temp. $1=$ temperatura média do mês anterior. Temp. 2 = temperatura média do segundo mês anterior.

As demais fenofases dessas espécies e de Alchornea e Cecropia apresentaram pouca relação com o clima que, quando existiu, alcançou no máximo $50 \%$.
O resultado do teste de Runs encontra-se na Tabela 5, que apresenta apenas as espécies nas quais se detectou dependência da freqüência de ocorrência das fenofases em relação à precipitação

TABELA 5

Valores de $p$ obtidos no Teste de Runs.

\begin{tabular}{|c|c|c|c|c|c|c|c|}
\hline Espécie & Fenofase & Precip. 0 & Precip. 1 & Precip. 2 & Temp. 0 & Temp. 1 & Temp. 2 \\
\hline \multirow{2}{*}{ Alchornea } & Floração & 0,69 & 0,28 & 0,78 & $0,04 *$ & 0,53 & 0,46 \\
\hline & Frutificação & $0,02 *$ & 0,39 & 0,83 & 0,62 & 0,89 & 0,12 \\
\hline \multirow{2}{*}{ Cedrela } & Floração & $0,01 *$ & 1,00 & $0,01 *$ & 1,00 & 1,00 & $* *$ \\
\hline & Frutificação & $0,04 *$ & $0,04 *$ & $* *$ & $* *$ & $0,04 *$ & 0,82 \\
\hline \multirow{3}{*}{ Cordia } & Floração & 0,10 & 0,46 & $0,01 *$ & 0,86 & 0,10 & $* *$ \\
\hline & Frutificação & $* *$ & 0,56 & 0,07 & $* *$ & 0,83 & 0,17 \\
\hline & Folhas caídas & $* *$ & 0,69 & $* *$ & 0,69 & 0,15 & $* *$ \\
\hline \multirow{2}{*}{ Croton } & Floração & 0,44 & 0,21 & 0,79 & 0,21 & $0,02 *$ & $0,02 *$ \\
\hline & Frutificação & 0,16 & 0,75 & 0,68 & $0,01 *$ & 0,75 & 0,68 \\
\hline
\end{tabular}

$* \mathrm{p}<0,05 ; * * \mathrm{p}<0,01$. Legenda das variáveis climáticas como na Tabela 3 . 
e à temperatura. Cecropia e Cupania apresentaram um comportamento aleatório em relação às variáveis climáticas analisadas. Nas demais espécies, a floração e a frutificação foram dependentes da precipitação e da temperatura de maneiras diferentes entre si e entre os vários períodos analisados. Apenas em Cordia detectou-se dependência da queda de folhas por fatores climáticos.

\section{DISCUSSÃO}

As análises circulares apresentaram grande correspondência com as análises descritivas convencionais e, apesar de não constituírem testes estatísticos, os valores de médias e variâncias circulares calculados são mais precisos para orientar a discussão dos resultados. O teste de significância dos ângulos médios (teste de Rayleigh) exige que os dados sejam independentes entre si (Fisher, 1993), o que significa que a cada mês deveria ser observado um indivíduo diferente de cada espécie, envolvendo uma grande quantidade de indivíduos amostrados. No presente estudo, foram observados sempre os mesmos indivíduos, caracterizando dados dependentes, impedindo, assim, que fosse realizado o teste de significância dos ângulos médios.

$\mathrm{O}$ atual estudo encontrou relações mais fortes entre as variáveis climáticas e a freqüência de ocorrência das fenofases quando temperatura e precipitação foram analisadas conjuntamente do que quando a análise foi feita em separado. $\mathrm{Na}$ maioria das vezes, esse aumento foi substancial, indicando a importância de analisar em conjunto todos os elementos do clima. Esse fato reforça a idéia de que a fenologia das espécies deve ser influenciada pela ação conjunta dos fatores climáticos, associados às características inerentes às espécies. Portanto, à medida que se considerar um maior número de fatores climáticos na análise, como, por exemplo, temperatura, precipitação, radiação solar, número de horas de insolação, umidade do ar e do solo, esperamos encontrar uma maior relação do clima com a fenologia das espécies.

\section{Floração}

Este estudo fornece evidências de que a floração está mais relacionada com os elementos do clima do segundo mês que antecede a floração do que com o período de produção de flores. Isso sugere que o clima do período que antecede a floração pode estar estimulando o desenvolvimento dos botões florais.

Todas as espécies aqui estudadas apresentaram pico de floração no período de transição entre as estações seca e úmida, com exceção de Cecropia. Morellato (1992) comentou que o aumento da temperatura, da precipitação e do comprimento do dia podem influenciar as espécies que florescem nessa época.

Cedrela floresceu em novembro e dezembro, depois do período de brotamento explosivo (outubro). Esse padrão concorda com a explicação de Reich \& Borchert (1984), de que em árvores com copa densa ("broadleaved trees") as flores podem abrir um pouco depois do crescimento sazonal dos ramos ou, como na maioria das espécies decíduas, depois de um período de dormência dos botões florais, que acontece quando as árvores estão sem folhas. Segundo estes autores, em árvores decíduas, como Cedrela, a antese pode ser induzida pela reidratação temporária das árvores depois da queda de folhas, por chuva isolada durante a estação seca ou pelo início da estação úmida. A reidratação das árvores, que previamente apresentam estresse hídrico, serve como estímulo para quebrar a dormência dos botões florais (Reich $\&$ Borchert, 1984).

Cordia e Croton floresceram no início da estação úmida, com pico de floração em novembro. Alchornea, apesar de florescer várias vezes durante o ano, apresentou maior produção de flores entre setembro e novembro. O pico de floração nessa época permite que haja um pico de frutificação na estação úmida (Jackson, 1978), favorecendo a germinação e o estabelecimento das plântulas.

A região do presente estudo mostrou sazonalidade no balanço hídrico, apresentando períodos com menor precipitação, porém com apenas dois meses de deficiência hídrica no solo. Apesar desse período seco, parece que a floração das espécies estudadas não foi afetada, apresentando o mesmo padrão em anos diferentes. Alencar (1994) sugeriu que os padrões fenológicos seriam mais afetados pelas características intrínsecas às espécies (genéticas, fisiológicas, reprodutivas) e pelos fatores ecológicos (polinização, predação, competição) do que somente pela influência das variáveis climáticas. Em climas sazonais existe flutuação na disponibilidade de polinizadores, dispersores, predadores e competidores (Lieberman, 1982), e 
as atividades destes agentes podem funcionar como forças seletivas para a sazonalidade dos eventos reprodutivos das plantas (Janzen, 1967).

Alchornea, Cedrela, Cordia e Croton apresentaram picos de floração na mesma época em que a maioria das espécies da comunidade (Rossi 1994), caracterizando sincronia interespecífica na floração.

A sincronia entre diferentes espécies possui a vantagem de atrair um maior número de polinizadores, além de saciar os predadores de flores (Janzen, 1975), e a desvantagem da possibilidade de transferência de pólen entre espécies diferentes (Rathcke \& Lacey, 1985). Stiles (1979) comentou que a assincronia interespecífica na floração poderia ser favorecida a fim de evitar a competição por polinizadores, espalhando os picos de floração em direção a uma distribuição uniforme através do tempo. Entretanto, o autor complementa que a extensão que essa distribuição pode atingir será limitada pelas restrições fisiológicas impostas às plantas pelo regime sazonal do hábitat em que elas se encontram. A competição por polinizadores deve ser um importante fator de seleção para as espécies da mata da CUASO por ser um fragmento isolado, devido ao fato de que a competição deve ser mais intensa entre espécies que ocorrem em áreas fragmentadas, visto que a polinização e a produção de sementes diminuem com a fragmentação (Aizen \& Feisinger, 1994).

As espécies deste estudo apresentaram alta sincronia intraespecífica na floração, com exceção de Cecropia. Um dos principais fatores que exercem pressão para a seleção da sincronia intraespecífica é a necessidade de polinização cruzada (Janzen, 1975). Nesse caso, seria mais vantajoso que cada indivíduo possuísse um número reduzido de flores, de modo a não saciar os polinizadores que se alimentam de pólen ou néctar, obrigando-os a visitar outros indivíduos em busca de mais flores, favorecendo a polinização cruzada.

As espécies aqui estudadas não apresentaram perfeita coincidência entre as épocas de floração e de frutificação quando comparadas com outros estudos (Hasui, 1994; Roizman, 1993; Rossi, 1994) e com outras áreas (Carvalho, 1994; Lorenzi, 1992; Morellato \& Leitão-Filho, 1992; Penhalber, 1995; Reitz, 1970, 1980). Este estudo não detectou nenhum episódio reprodutivo em Cupania, enquanto foram observados indivíduos desta espécie flo- rescendo no Parque Municipal Alfredo Volpi, que dista cerca de $3 \mathrm{~km}$ da mata da CUASO, na mesma época do estudo. A falta de correspondência pode ser devida à variação fenológica intra-específica, bem como a diferenças ambientais na área de distribuição das espécies. Outra possibilidade é que o tempo de acompanhamento dos estudos nem sempre é longo o suficiente para detectar padrões supra-anuais de floração. Apesar do pequeno número de indivíduos observados, as espécies aqui estudadas apresentaram grande correspondência entre os anos, o que sugere que os padrões encontrados caracterizam satisfatoriamente as populações da mata da CUASO.

O padrão bianual de floração e frutificação apresentado por Cedrela concorda com o encontrado por Morellato \& Leitão-Filho (1990) em área de floresta mesófila na Serra do Japi. Janzen (1976) indicou que espécies que florescem bianualmente podem apresentar floração nos intervalos, com função de manutenção dos polinizadores, conforme observado aqui, com um único indivíduo em flor em 1994. Segundo Whitmore (1990), espécies climácicas em florestas úmidas possuem um evento principal de floração por ano, geralmente na mesma época, e espécies pioneiras têm floração contínua, apresentando alguns eventos reprodutivos por ano ou produzindo flores continuamente durante todo o ano. Alchornea e Cecropia fazem parte do grupo de espécies pioneiras, enquanto Cedrela, Cordia, Croton e, provavelmente, Cupania estão mais próximas do grupo das espécies tardias, segundo a periodicidade da floração.

\section{Frutificação}

O presente estudo constatou que a frutificação em Cordia, Croton e Cedrela esteve relacionada à precipitação e à temperatura do período de produção dos frutos. Porém, a influência do clima mostrou-se bastante complexa, uma vez que cada elemento climático parece ter um peso diferente na fenologia das espécies, de acordo com o período analisado.

Somente em Cordia a frutificação apresentou dependência significativa da temperatura e da precipitação na época de produção dos frutos. Provavelmente, a frutificação está relacionada a outros fatores que não apenas os climáticos, que selecionaram a época mais favorável para a produção dos frutos. 
Foster (1992) sugere que a época de frutificação das espécies é controlada pela época que apresenta as condições mais favoráveis para a germinação das sementes. A produção e a queda de frutos no final da estação seca e início da úmida seria vantajosa para as sementes, sendo que elas teriam maior possibilidade de germinação e crescimento das plântulas devido à umidade (Janzen, 1967), já que estas teriam toda a estação úmida para desenvolver o sistema radicular antes da próxima estação seca (Morellato \& Leitão-Filho, 1992).

Existe uma forte relação entre a época de produção de frutos, o tipo de fruto (seco ou carnoso) e a síndrome de dispersão das espécies (Frankie et al., 1974; Morellato, 1992). De acordo com Morellato \& Leitão-Filho (1990, 1992), das espécies que floresceram em setembro e outubro, aquelas que possuíam frutos carnosos apresentaram frutos maduros na estação úmida e as que possuíam frutos secos, zoocóricos ou anemocóricos frutificaram na estação seca seguinte. De modo geral, as espécies deste estudo concordaram com este padrão: Cordia produz frutos carnosos e frutificou na estação úmida; Cedrela possui frutos secos e sementes aladas anemocóricas, e dispersou suas sementes na estação seca seguinte à da floração. Croton tem frutos secos autocóricos e, no entanto, apresentou pico de frutificação na estação úmida. As sementes de Croton possuem viabilidade curta, não ultrapassando quatro meses (Carvalho, 1994), sendo que o pico de frutificação no início da estação úmida favorece a germinação rápida, na época mais favorável para o estabelecimento das plântulas. Alchornea, com frutos secos e sementes dispersas por animais, floresceu e frutificou durante praticamente o ano inteiro, com pico de frutificação em outubro.

Em espécies decíduas, como Cedrela, a estação seca representa a época mais favorável para a dispersão das sementes, sendo que esta espécie apresentou pico de frutificação entre junho e agosto. A dispersão em Cedrela também é favorecida pela posição das árvores no dossel e como emergentes na mata (Morellato \& Leitão-Filho, 1992).

$\mathrm{Na}$ área deste estudo, a maioria das espécies zoocóricas frutificou em outubro e novembro (39 e 26 espécies, respectivamente), na época de transição entre as estações seca e úmida (Hasui, 1994). Apesar de frutificar várias vezes por ano, $A l$ chornea apresentou pico de produção de frutos em outubro, coincidindo com a época em que existem mais espécies produzindo frutos na mata. A competição entre espécies por animais dispersores deve ser maior no início da estação úmida, por haver um maior número de espécies frutificando nessa época. Isto deve exercer uma pressão para o deslocamento da época de frutificação para um outro período (Foster, 1992), o que pode ter acontecido com Cordia, que apresentou frutificação maciça em janeiro, fevereiro e março, coincidindo com um menor número de espécies frutificando na mata $(19,18$ e 15 espécies, respectivamente) (Hasui, 1994).

Alchornea e Cecropia foram registradas na dieta de aves da mata da CUASO, e Cordia e Cupania não foram encontradas, porém são espécies zoocóricas potencialmente utilizadas pelas aves (Hasui, 1994). Esta autora encontrou um número menor de espécies de aves frugívoras nessa mata, comparada com fragmentos maiores na mesma região. As espécies amostradas visitaram mais as plantas da borda da mata, sendo que a ausência de frugívoros dispersores pode prejudicar o sucesso reprodutivo das plantas do interior da mata, porque as sementes acabam caindo sob a plantamatriz, onde a mortalidade é muito grande (Howe \& Smallwood, 1982). Hasui (1994) registrou um baixo índice de recaptura das aves fora da mata, sugerindo que elas se deslocam pouco entre a mata e seus arredores, o que reforça a idéia do isolamento e da limitada possibilidade de dispersão das espécies da mata, bem como na chegada restrita de propágulos de espécies nativas.

\section{Queda de folhas e brotamento}

A queda de folhas em Cordia foi significativamente dependente da precipitação e da temperatura no segundo mês que antecedeu à perda das folhas, assim como dependeu da precipitação no mesmo mês da queda. Apesar disso, a freqüência de indivíduos com perda de folhas variou muito pouco, sendo igual a $100 \%$ em quase todos os meses. Nas demais espécies, em todas as análises, encontraram-se relações muito fracas entre os fatores climáticos e a perda de folhas, indicando que a influência do clima é bastante complexa.

$\mathrm{O}$ estresse hídrico e a disponibilidade de nutrientes podem influenciar a maior queda de folhas na estação seca (Jordan, 1983). A deficiência hídrica temporária é importante mesmo em climas prati- 
camente uniformes, com chuvas bem distribuídas (Koriba, 1958 apud Morellato, 1992). No caso da mata da CUASO, houve apenas um curto período, de dois meses, de déficit hídrico no solo que, aparentemente, não intensificou a queda de folhas nem retardou o brotamento nas espécies estudadas.

Espécies de árvores tropicais podem variar de sempre-verdes até decíduas, dependendo do grau de seca sazonal e do seu potencial de reidratação e controle da perda d'água (Reich \& Borchert, 1984). As espécies do atual estudo, com exceção de Cedrela, apresentaram padrão contínuo de queda e de brotamento de folhas, mostrando sazonalidade na intensidade com que ocorreram. De acordo com Jackson (1978), a estratégia de reposição de folhas mais vantajosa numa planta perene, em um ambiente não-estacional, seria a retenção e a manutenção da atividade fotossintética da folhas velhas até o crescimento das folhas novas. Essa estratégia resulta em perda contínua de folhas, se o brotamento for contínuo, que é o caso das espécies do atual estudo. Reich \& Borchert (1984) encontraram, em sítios úmidos, muitas espécies que permaneceram sempre-verdes, brotando ao mesmo tempo que perdiam as folhas velhas.

Em muitas espécies tropicais, a reidratação das árvores, que acontece após a queda das folhas, nem sempre induz o brotamento, e as árvores ficam dormentes durante um certo período. Por exemplo, em áreas sem uma estação seca pronunciada, árvores do gênero Cedrela permanecem sem folhas por vários meses (Reich \& Borchert, 1984). Isso aconteceu com C.fissilis na mata da CUASO, que não apresentou uma estação seca bem definida. O período em que os indivíduos sofrem deficiência hídrica pode ser um pré-requisito para quebrar a dormência dos brotos, de forma que um período mais seco, seguido das primeiras chuvas, pode ser o estímulo para o início do crescimento vegetativo (Lieberman, 1982). Isso pode ter acontecido com Cedrela, que apresentou a maior sincronia no brotamento dentre as espécies deste estudo, com todos os indivíduos brotando entre setembro e outubro, após um período de três meses sem folhas.

O clima exerce influência distinta em fenofases e espécies diferentes. A floração em Cordia, Croton e Cedrela relacionou-se com a temperatura e a precipitação de dois meses anteriores ao evento, enquanto a frutificação esteve relacionada com estes fatores climáticos no mesmo período de produção dos frutos. A queda de folhas esteve relacionada com a temperatura e a precipitação somente em Cordia. O brotamento em Cedrela relacionou-se com os elementos climáticos de dois meses anteriores ao evento, enquanto em Cupania e Cordia a relação foi com o clima do período de produção das folhas. Espécies de diferentes grupos ecológicos e síndromes de dispersão possuem estratégias fenológicas distintas. As espécies pioneiras, Alchornea e Cecropia, apresentaram mais de um evento reprodutivo por ano, enquanto Cedrela, Cordia e Croton, que são secundárias, caracterizaram-se por apresentar reprodução anual ou em intervalos maiores. As espécies zoocóricas frutificaram, principalmente, na estação úmida, independente do tipo de fruto produzido, enquanto Cedrela dispersou suas sementes em sincronia com a época em que as copas estavam sem folhas. Todas as espécies apresentaram queda e brotamento de folhas durante o ano inteiro, variando a intensidade, com exceção de Cedrela, em que o brotamento se concentrou na transição entre a época seca e a úmida.

$\mathrm{O}$ presente trabalho evidencia a necessidade de estudos aprofundados sobre a fenologia de espécies arbóreas tropicais e sua relação com os fatores climáticos. A previsão da época de ocorrência das fenofases depende do conhecimento das respostas das espécies à ação conjunta dos elementos do clima. Da mesma forma, faz-se necessário investir em estudos fenológicos de longo prazo, envolvendo espécies de diferentes grupos ecológicos, para que se possa conhecer os ciclos de crescimento e de reprodução da floresta como um todo.

Agradecimentos - A A. L. S. Samartini, G. E. Dumbra, C. D. Saldiva de André e S. N. Elian, do Instituto de Matemática e Estatística da USP, pela realização das análises estatísticas preliminares que direcionaram as análises apresentadas neste trabalho. A J. C. Voltolini pelo incentivo e sugestões. Este trabalho faz parte da Dissertação de Mestrado de D. K. Ferraz, que recebeu apoio da Fapesp, proc. no 94/4093-0 e 94/5539-2.

\section{REFERÊNCIAS BIBLIOGRÁFICAS}

AIZEN, M. A. \& FEISINGER, P., 1994, Forest fragmentation, pollination, and plant reproduction in a Chaco Dry Forest, Argentina. Ecology, 75(2): 330-351.

ALENCAR, J. C., 1994, Fenologia de cinco espécies arbóreas tropicais de Sapotaceae, correlacionada a variáveis climáticas na Reserva Ducke, Manaus, AM. Acta Amaz., 24(3/4): 161-182. 
BUSSAB, W. O. \& MORETTIN, P. A., 1986, Estatística básica. 3ㄹed., Atual, São Paulo, 321p.

CERSÓSIMO, L. F., 1993, Variações espaciais e temporais no estabelecimento de plântulas em trecho de floresta secundária em São Paulo, SP. Dissertação de Mestrado, IBUSP, São Paulo, 195p.

CARVALHO, P. E. R., 1994, Espécies florestais brasileiras. Recomendações silviculturais, potencialidades e uso da madeira. Embrapa-CNPF/SPI, Brasília, 676p.

FERRAZ, D. K., 1997, Dinâmica de seis populações de árvores em fragmento de mata em São Paulo, SP. Dissertação de Mestrado, IBUSP, São Paulo, 99p.

FISHER, N. I., 1993, Statistical analysis of circular data. University Press, Cambridge, 277p.

FOSTER, R. B., 1992, Ciclo estacional de caída de frutos en la isla de Barro Colorado. In: E. G. Leigh, A. S. Rand \& D. M. Windsor (eds.), Ecología de un bosque tropical, Smithsonian Tropical Research Institute, Balboa, pp. 219-241.

FRANKIE, G. W., BAKER, H. G. \& OPLER, P. A., 1974, Comparative phenological studies of trees in tropical wet and dry forests in the lowlands of Costa Rica. J. Ecol., 62(3): 881-913.

GIBBONS, J. D., 1981, Tests of randomness. In: S. Kotz \& N. L. Johnson (eds.), Encyclopedia of Statistical Science, John Wiley \& Sons, New York, v. 7, pp. 555-562.

GOMES, E. P. C., 1992, Fitossociologia do componente arbóreo de um trecho de mata em São Paulo, SP. Dissertação de Mestrado, IBUSP, São Paulo, 143p.

HASUI, E., 1994, O papel das aves frugívoras na dispersão de sementes em um fragmento de floresta estacional semidecídua secundária em São Paulo, SP. Dissertação de Mestrado, IBUSP, São Paulo.

HOWE, H. F. \& SMALLWOOD, J., 1982, Ecology of seed dispersal. Ann. Rev. Ecol. Sys., 13: 201-208.

JACKSON, J. F., 1978, Seasonality of flowering and leaffall in a Brazilian subtropical lower montane moist forest. Biotropica, 10(1): 38-42.

JANZEN, D. H., 1967, Synchronization of sexual reproduction of trees within the dry season in Central America. Evolution, 21: 620-37.

JANZEN, D. H., 1975, Ecologia vegetal nos trópicos. EPU e Edusp, São Paulo.

JANZEN, D. H., 1976, Seeding patterns of tropical trees. In: P.B. Tomlinson \& M. H. Zimmerman (eds.), Tropical trees as living systems, Cambridge University Press, Cambridge, pp. 88-128.

JORDAN, C. F., 1983, Productivity of tropical rain forest ecosystems and the implications for their use as future wood and energy sources. In: F. B. Golley (ed.), Tropical rain forest ecosystems - structure and function, pp. 117-136.

KOEPPEN, W., 1948, Climatologia: con un estudio de los climas de la tierra. Mexico, Fundo de Cultura Economica, 478p.

LIEBERMAN, D., 1982, Seasonality and phenology in a dry forest in Ghana. J. Ecol., 70: 791-806.
LORENZI, H., 1992, Árvores brasileiras. Manual de identificação e cultivo de plantas arbóreas nativas do Brasil. Ed. Plantarum, Nova Odessa, 368p.

MONTGOMERY, D. C. \& PECK, E. A., 1982, Introduction to linear regression analysis. John Wiley \& Sons, New York, 504p.

MORELLATO, L. P. C., 1992, Sazonalidade e dinâmica de ecossistemas florestais na Serra do Japi. In: L. P. C Morellato (org.), História natural da serra do Japi. Ecologia e preservação de uma área de floresta no sudeste do Brasil, Ed. Unicamp/Fapesp, Campinas, pp. 98-110.

MORELlATO, L. P. C. \& LEITÃO-FILHO, H. F., 1990, Estratégias fenológicas de espécies arbóreas em floresta mesófila na serra do Japi, Jundiaí, São Paulo. Rev. Brasil. Biol., 50(1): 163-173.

MORELlATO, L. P. C. \& LEITÃO-FILHO, H. F., 1992, Padrões de frutificação e dispersão na serra do Japi. In: L. P. C. Morellato (org.), História natural da serra do Japi. Ecologia e preservação de uma área de floresta no sudeste do Brasil, Ed. Unicamp/Fapesp, Campinas, pp.112-140.

MORELLATO, L. P. C., LEITÃO-FILHO, H. F., RODRIGUES, R. R. \& JOLY, C. A., 1990, Estratégias fenológicas de espécies arbóreas em floresta de altitude na serra do Japi, Jundiaí, São Paulo. Rev. Brasil. Biol., 50(1): 149-162.

MORELLATO, L. P. C., RODRIGUES, R. R., LEITÃOFILHO, H. F. \& JOLY, C. A., 1989, Estudo fenológico comparativo de espécies arbóreas de floresta de altitude e floresta mesófila semidecídua na serra do Japi, Jundiaí, SP. Rev. Brasil. Bot., 12: 85-98.

NEWSTROM, L. E. FRANKIE, G. W. \& BAKER, H. G., 1994, A new classification for plant phenology based on flowering patterns in lowland tropical rain forest trees at La Selva, Costa Rica. Biotropica, 26(2): 159-141.

PENHALBER, E. F., 1995, Fenologia, chuva de sementes e estabelecimento de plântulas em um trecho de mata em São Paulo, SP. Dissertação de Mestrado, IBUSP, São Paulo, 124p.

PEREIRA, R. A. S., RODRIGUES, E. \& MENEZES JR., A. O., 1995, Fenologia de Ficus guaranitica Chodat \& Vischer. Semina: Ci. Agr., 16: 129-135.

RATHCKE, B. \& LACEY, E. P., 1985, Phenological patterns of terrestrial plants. Ann. Rev. Ecol. Syst., 16: 179-214.

REICH, P. B. \& BORCHERT, R., 1984, Water stress and tree phenology in a tropical dry forest in the lowlands of Costa Rica. J. Ecol., 72: 61-74.

REITZ, R., 1970, Flora ilustrada catarinense. Boragináceas. Itajaí, 85p.

REITZ, R., 1980, Flora ilustrada catarinense. Sapindáceas. Itajaí, $156 \mathrm{p}$.

ROIZMAN, L. G., 1993, Fitossociologia e dinâmica do banco de sementes de populações arbóreas de floresta secundária em São Paulo, SP. Dissertação de Mestrado, IBUSP, São Paulo, 184p.

ROSSI, L., 1994, A flora arbóreo-arbustiva da mata da reserva da Cidade Universitária "Armando de Salles Oliveira" São Paulo. Boletim do Instituto de Botânica, 9: 1-105. 
STILES, F. G., 1979, Regularity, randomness, and aggregation in flowering phenologies. Science, 203: 471.

VAN SCHAIK, C., TERBORGH, J. W. \& WRIGHT, S. J., 1993, The phenology of tropical forests: adaptative significance and consequences for primary consumers. Annu. Rev. Ecol. Syst., 24: 353-377.

VELOSO, H. P. \& GÓES FILHO, L., 1982, Fitogeografia brasileira, classificação fisionômica ecológica da vegetação neotropical. Bol. Técnico, Projeto RADAMBRASIL, Sér. Vegetação, Salvador, no 1 .
WHITMORE, T. C., 1990, An introduction to tropical rain forests. Seasonal rhythms. Clarendon Press., Oxford, pp. 52-57.

WINDSOR, D. M., MORRISON, D. W., ESTRIBI, M. A. \& LEON, B., 1989, Phenology of fruit and leaf production by "strangler" figs on Barro Colorado Island, Panamá. Experientia, 45: 647-653. 